\title{
气孔运动中的活性氧信号
}

\author{
王棚涛, 赵晶, 余欢欢 \\ 河南大学生命科学学院/棉花生物学国家重点实验室/河南省植物逆境生物学重点实验室, 开封 475004
}

\begin{abstract}
摘要 大量研究证明活性氧(ROS)在气孔运动中起信号分子的作用。保卫细胞中ROS的产生依赖于特定的酶, 其中NADPH 氧化酶组分 $R B O H$ 已得到深入研究, 并已证实其参与生物与非生物胁迫反应。植物激素包括脱落酸(ABA)、水杨酸 $(S A) 、 乙$ 烯、生长素及细胞分裂素等, 它们均通过ROS的介导来调控气孔运动。生物胁迫(如毒性细菌和真菌)也会调控气孔运动。 ROS参与这些调控过程。保卫细胞中存在多层次对ROS产生及其作用的调节, 抗氧化活性物质和ROS敏感蛋白(如蛋白激 酶和磷酸酶)均可传递ROS信号并调节气孔运动。ROS对离子通道调节的证据也越来越多。保卫细胞由于可通过ROS整合 复杂的信号途径, 已成为研究植物ROS信号转导过程的良好模式系统。
\end{abstract}

关键词 保卫细胞, 活性氧, 气孔

王棚涛, 赵晶, 余欢欢 (2014). 气孔运动中的活性氧信号. 植物学报 49, 490-503.

植物叶片表皮上由 2 个保卫细胞围成的气孔是光 合作用 $\mathrm{CO}_{2}$ 进入叶片的通道。蒸腾作用水分的散失与 光合作用 $\mathrm{CO}_{2}$ 的吸收之间的平衡调节通过气孔开闭 (对环境变化的感应)而实现。气孔开闭运动又受保卫 细胞的膨压调节(Blatt, 2000)。气孔对多种刺激非常 敏感, 如光照、干旱胁迫以及病原菌攻击等。气孔开 闭失调将对植物产生不利影响。调控气孔运动的信号 途径或网络的复杂性反映了多种外界刺激均可调节 气孔开闭运动。

活性氧(reactive oxygen species, ROS)产生于 分子氧的不完全还原形成的具活跃化学反应性质的 氧分子, 包括超氧自由基 $\left(\mathrm{O}_{2}{ }^{\circ}\right)$ 、过氧化氢 $\left(\mathrm{H}_{2} \mathrm{O}_{2}\right)$ 、单 线态氧 $\left({ }^{1} \mathrm{O}_{2}\right)$ 和羟自由基 $(\cdot \mathrm{OH})$ 等。 $\mathrm{H}_{2} \mathrm{O}_{2}$ 由于较为稳定 因而受到广泛研究。传统概念认为, 高浓度ROS对生 命有机体具有毒害作用。然而, 目前认为低浓度的 ROS可作为重要的第二信使分子介导多种环境刺激 反应。最近几十年人们已在多种植物细胞中对ROS 的信号作用进行了广泛研究(Apel and Hirt, 2004)。植 物细胞在应对多种刺激时均会产生ROS, 包括植物 激素、干旱、极端温度、光强变化、空气污染、病原 菌及向地性等发育信号(Desikan et al., 2005a)。保卫 细胞可通过ROS含量变化整合各种外界刺激信号,
并且气孔对刺激的反应可量化为简单的气孔开度变 化, 因而保卫细胞已成为研究植物细胞信号的模式系 统(Schroeder et al., 2001)。本文概述了保卫细胞产 生ROS的多种途径及诱导气孔关闭的外界环境刺激。

\section{1 气孔开闭运动机制}

人们对于植物控制气孔开度的细胞学机制已有较清 晰的了解。气孔开度变化通过调节保卫细胞膨压和体 积的变化来实现。保卫细胞膨压升高, 气孔张开; 保 卫细胞膨压下降, 气孔关闭。这种气孔开闭运动通过 调节跨越保卫细胞质膜的离子流动而实现。质膜上的 质子泵 $\left(\mathrm{H}^{+}\right.$-ATPase $)$被激活时将大量 $\mathrm{H}^{+}$外排, 造成胞 外酸化、胞内碱化, 质膜超极化, 进而通过内向整合 $\mathrm{K}^{+}$通道 $\left(\mathrm{K}^{+}{ }_{\text {in }}\right)$ 吸收 $\mathrm{K}^{+}$, 同时使 $\mathrm{Cl}^{-}$进入保卫细胞, 导致 保卫细胞离子浓度增加及膨压升高, 气孔开放。气孔 关闭时, 质膜 $\mathrm{H}^{+}$-ATPase活性受抑制, 保卫细胞胞内 $\mathrm{Ca}^{2+}$ 浓度升高, 导致质膜去极化, $\mathrm{Cl}^{-}$通过慢速(S)或 快速 $(R)$ 阴离子通道外流，质膜去极化同时抑制 $\mathrm{K}^{+}$in, 激活外向整合 $\mathrm{K}^{+}$通道 $\left(\mathrm{K}^{+}\right.$out $)$, 导致 $\mathrm{K}^{+}$外流, 保卫细胞 膨压下降, 气孔关闭。 $\mathrm{Ca}^{2+}$ 也参与气孔运动的调节, 并介导脱落酸(abscisic acid, ABA) 诱导的气孔关闭

收稿日期: 2013-05-13; 接受日期: 2013-07-17

基金项目: 国家自然科学基金(No.31170253)

* 通讯作者。E-mail: wangpt126@126.com 
过程(Blatt, 2000; Schroeder et al., 2001; Daszkowska-Golec and Szarejko, 2013)。

\section{2 活性氧的来源}

植物细胞正常代谢过程中有多条途径可以产生ROS, 包括叶绿体、线粒体和过氧化物酶体等(Neill et al., 2002; Desikan et al., 2005a)。除了这种正常代谢产 生的ROS外, 植物还可通过特异的酶途径催化产生 ROS, 以应对各种外界刺激。其中, 对于能够产生 ROS的NADPH氧化酶(NOX)已有较深入的研究。拟 南芥(Arabidopsis thaliana)有10个NOX基因, 由于这 些基因与哺乳动物 $N O X$ 基因 $g p 91^{\text {phox }}$ 同源, 故被命名 为AtrbohA $J$ (意指拟南芥中的氧化猝发同源物)。这些 基因具有各自特异的组织表达特性(Torres et al., 1998; Kwak et al., 2003; Sagi and Fluhr, 2006)。这 10个基因中, AtrbohD和AtrbohF在保卫细胞中表达, 并在ABA诱导的气孔关闭中起重要作用(Kwak et al., 2003)。Keller等(1998)的研究表明, AtrbohF与质膜结 合。Torres等(1998)发现所有的Atrboh基因序列都含 有质膜定位结构域。早期研究还表明 AtrbohD和 AtrbohF参与植物的抗病反应(Torres et al., 2002)。

除NOX外, 过氧化物酶、黄嘌呤氧化酶、草酸氧 化酶以及胺氧化酶也可作为植物细胞的 ROS来源 (del Río et al., 2002; Mittler, 2002; Desikan et al., 2005a)。过氧化物酶存在于细胞壁中, 并参与水杨酸 (salicylic acid, SA) 诱导的气孔关闭 (Mori et al., 2001), 且在病原菌侵染时诱导ROS的产生(Bolwell et al., 2002)。然而, 过氧化物酶的底物还未得到鉴定 (Bolwell et al., 2002)。黄嘌呤氧化酶存在于过氧化物 酶体内, 并催化产生 $\mathrm{O}_{2}$ - 和氧化黄嘌呤, 将次黄嘌呤 氧化为尿酸(del Río et al., 2002)。

保卫细胞叶绿体被认为是具有调节气孔运动功 能的特异细胞器, 保卫细胞叶绿体产生ROS对于气 孔运动调节具有特殊意义。与叶肉细胞叶绿体相比, 保卫细胞叶绿体更小, 并且类囊体片层更少。保卫细 胞叶绿体的数目只有叶肉细胞叶绿体数目的 $1 / 3$, 且 每个保卫细胞的叶绿素含量只相当于叶肉细胞叶绿 素含量的1\%-4\%。生物化学研究表明, 保卫细胞叶绿 体存在卡尔文循环酶。然而保卫细胞中卡尔文循环的 关键酶Rubisco活性极低。考虑到保卫细胞较低的叶
绿素含量和Rubisco活性, 保卫细胞 $\mathrm{CO}_{2}$ 固定能力大 约只有叶肉细胞的 2\%-4\%。转基因烟草(Nicotiana tabacum)减少Rubisco含量并抑制光合作用表明光合 能力与高光下气孔导度可能无直接关系。然而, 尽管 保卫细胞叶绿体小、数量少、基粒片层少, 但光合磷 酸化能力高达叶肉细胞的 $80 \%$ 。这暗示了过剩的光能 到化学能的转变为产生大量的ROS提供了可能性。因 此保卫细胞叶绿体不仅提供能量, 而且可能作为环境 氧化还原信号的感受体起作用, 使植物更好地适应环 境变化(Wang and Song, 2008)。

\section{3 引发ROS产生的外界刺激}

从进化的角度看, $\mathrm{H}_{2} \mathrm{O}_{2}$ 无疑是一个古老的信号, 因为 氧化还原反应本身就是生命的基本过程。 $\mathrm{H}_{2} \mathrm{O}_{2}$ 在细胞 内许多生理生化过程、信号转导甚至基因转录等方面 起重要作用(Cheng and Song, 2006)。大量 的研究 表明, 多种胁迫刺激均可引发ROS的产生, 因而人们 常把ROS含量升高作为细胞遭受生物与非生物胁迫 的指示剂(Mittler, 2002)。

\subsection{ROS信号与植物激素}

McAinsh等(1996)以鸭跖草(Commelina communis) 为材料, 发现ROS可以诱导气孔关闭, 抑制气孔张 开, 并且这一作用与胞质中 $\mathrm{Ca}^{2+}$ 浓度 $\left(\left[\mathrm{Ca}^{2+}\right]_{\mathrm{cyt}}\right)$ 升高 有关。其中低浓度的ROS通过 $\mathrm{Ca}^{2+}$ 调控可逆的气孔运 动; 而高浓度的ROS导致保卫细胞活性丧失, 质膜完 整性受损, 诱导气孔不可逆关闭。这一过程不依赖于 $\mathrm{Ca}^{2+}$, 但此后未见其它关于ROS影响保卫细胞活性 的报道。由于技术的原因, 细胞中ROS的浓度一直无 法准确定量测定, 因此检验外源ROS的作用时只能 控制在一定的浓度范围内。

众所周知, 干旱胁迫下 $A B A$ 在调控气孔运动中起 着关键作用, 因而关于保卫细胞中 $A B A$ 信号转导的研 究积累了大量资料。苗雨晨等(2000)报道了 $A B A$ 可能 诱导蚕豆(Vicia faba)保卫细胞产生 $\mathrm{H}_{2} \mathrm{O}_{2}$ 。随后, Pei 等(2000)进一步证实 $\mathrm{H}_{2} \mathrm{O}_{2}$ 通过激活质膜 $\mathrm{Ca}^{2+}$ 通道介 导ABA诱导的拟南芥气孔关闭。Kwak等(2003)进一 步的研究表明, 拟南芥中 AtrbohD和AtrbohF两个 $N O X$ 基因参与 $A B A$ 诱导的气孔关闭过程。尽管 atrbohd和atrbohf单突变体的气孔开度在ABA处理下 
与野生型间的差异并不显著, 然而, atrbohdlf双突变 体显著削弱了ABA诱导的气孔关闭。这一结果也暗示 了AtrbohD和AtrbohF之间存在部分功能几余。与野生 型相比, atrbohdlf双突变体中ABA诱导ROS产生的量 变少, 而外源施加 $\mathrm{H}_{2} \mathrm{O}_{2}$ 处理可恢复atrbohdlf双突变 体的气孔关闭。这一结果将ABA诱导气孔关闭与通过 NOX产生 $\mathrm{H}_{2} \mathrm{O}_{2}$ 直接联系起来。Zhang等(2001)在蚕豆 中也证实ABA可通过激活NOX产生 $\mathrm{H}_{2} \mathrm{O}_{2}$ 进而诱导气 孔关闭。尽管ABA诱导的气孔关闭作用在atrbohdlf 双突变体中被明显削弱, 但并未完全被阻断(Kwak et al., 2003)。因而，暗示应该还存在来源于其它途径的 $\mathrm{H}_{2} \mathrm{O}_{2}$ 参与 $A B A$ 诱导的气孔关闭过程。令人兴奋的是, 在蚕豆保卫细胞中发现来源于质外体铜胺氧化酶产 生的 $\mathrm{H}_{2} \mathrm{O}_{2}$ 参与 $A B A$ 诱导的气孔关闭过程, 而且铜胺 氧化酶产生 $\mathrm{H}_{2} \mathrm{O}_{2}$ 的过程独立于质膜NOX。ABA处理 可激活质外体铜胺氧化酶, 通过降解腐胺产生 $\mathrm{H}_{2} \mathrm{O}_{2}$, 并引起胞质 $\mathrm{Ca}^{2+}$ 浓度升高, 诱导气孔关闭(An et al., 2008)。与ROS参与ABA诱导气孔关闭过程相类似, ROS也同样参与 $A B A$ 抑制的气孔张开过程, 外源 $\mathrm{H}_{2} \mathrm{O}_{2}$ 处理可以抑制气孔张开(Mishra et al., 2006; Yan et al., 2007)。但气孔张开与气孔关闭是两个完 全不同的过程, $\mathrm{H}_{2} \mathrm{O}_{2}$ 抑制气孔张开的机制目前还不清 楚。与 $\mathrm{H}_{2} \mathrm{O}_{2}$ 类似, 另外一种重要的信号分子一氧化氮 (NO) 在植物应答多种环境刺激时参与其中的信号途 径。Bright等(2006)证明在ABA诱导的气孔关闭中, $\mathrm{NO}$ 在 $\mathrm{H}_{2} \mathrm{O}_{2}$ 的下游起作用, 并且 $A B A$ 诱导 $N O$ 产生又 依赖于 $A B A$ 激活的AtrbohD和AtrbohF产生 $\mathrm{H}_{2} \mathrm{O}_{2}$ 。

研究显示, 拟南芥中磷脂酶Da1(PLDa1)及其酶 解产物磷脂酸(PA) 也参与 $A B A$ 诱导的保卫细胞ROS 产生过程(Zhang et al., 2009)。在plda1突变体中ABA 不能激活其 $\mathrm{NADPH}$ 氧化酶产生ROS, 但磷脂酶Da1 的酶解产物PA却可以正常激活plda1突变体NADPH 氧化酶产生ROS。在plda1突变体中还发现ABA诱导 的NO产生受阻。在这一信号途径中, PA一方面与 RbohD的N端互作使其激活产生ROS; 另一方面PA 还与 $A B I 1$ 互作, 将其募集于质膜而降低其PP2C磷酸 酶活性，从而怙抗ABI1对 $\mathrm{H}_{2} \mathrm{O}_{2}$ 和NO信号的抑制作用 (Zhang et al., 2009)。

乙烯 (ethylene) 可通过与ABA互作调节气孔开 度。有报道显示, 乙烯通过其受体 ETR1激活 AtrbohF(而不通过AtrbohD) 产生 $\mathrm{H}_{2} \mathrm{O}_{2}$ 并诱导拟南芥
气孔关闭 (Tanaka et al., 2005; Desikan et al., 2006)。此后, 利用拟南芥中 $\mathrm{H}_{2} \mathrm{O}_{2}$ 和 $\mathrm{H}_{2} \mathrm{~S}$ 合成缺失突 变体结合药理学实验进一步证明, 乙烯诱导的气孔关 闭过程中出现 $\mathrm{H}_{2} \mathrm{O}_{2}$ 含量升高, 并伴随胞质碱化, 此后 $\mathrm{NO}$ 的合成增加, 并进一步诱导 $\mathrm{H}_{2} \mathrm{~S}$ 合成, 最终导致 气孔关闭(刘菁等, 2010, 2011; 侯智慧等, 2012; 王 兰香等, 2012)。这些结果说明, 乙烯诱导的气孔关闭 过程与ABA诱导的气孔过程可能共享多种信号转导 组分。然而, 令人困惑的是, 乙烯有时可促进气孔关 闭(Pallas and Kays, 1982; Beguerisse-Dıaz et al., 2012), 有时又促进气孔张开(Madhavan et al., 1983; Levitt et al, 1987; Merritt et al., 2001)。这些实验结 果的原因还需要进一步分析。

除了 $A B A$ 和乙烯可诱导气孔关闭外, 另外一种参 与植物系统获得性抗性的激素水杨酸也可诱导䖯豆 保卫细胞产生ROS并导致气孔关闭 (Mori et al., 2001; Khokon et al., 2011)。与ABA诱导气孔关闭不 同的是, SA 诱导气孔关闭中ROS来源于细胞壁结合 的愈创木酚过氧化物酶, 而非质膜NOX(Mori et al., 2001)。这暗示了在植物中针对不同的刺激由不同的 ROS生成酶参与形成ROS, 从而使植物能够区分并 应对多种不同刺激, 进而作出精细的应答反应。然而, $\mathrm{SA}$ 诱导的气孔关闭同样需要胞外 $\mathrm{Ca}^{2+}$ 存在, 尽管未 检测到胞质 $\mathrm{Ca}^{2+}$ 水平升高, 说明 $\mathrm{ABA}$ 与 $\mathrm{SA}$ 诱导气孔 关闭的信号途径可能在ROS产生的下游享有共有成 分(Mori et al., 2001)。最近研究发现NO便是这种共 享组分之一, 其证据是拟南芥noa1突变体可明显抑 制SA诱导的NO产生及气孔关闭(Sun et al., 2010)。 同时, 硝酸还原酶NIA1和NIA2也参与SA诱导的NO 产生及气孔关闭(Hao et al., 2010)。这些结果表明, SA通过诱导NO合成而导致气孔关闭。

此外, 还发现茉莉酸甲酯(MeJA) 或茉莉酸 (jasmonic acid, JA) 同样可通过ROS的介导而诱导气 孔关闭(Suhita et al., 2004)。与ABA类似, JA同样不 能诱导atrbohdlf双突变体产生ROS以及气孔关闭, 暗示了 $\mathrm{NADPH}$ 氧化酶RBOH同样参与了 $\mathrm{JA}$ 诱导的气 孔关闭过程。与预期相符, JA不能诱导其不敏感突变 体jar1-1的气孔关闭, 但jar1-1突变体却可响应ABA 诱导的气孔关闭。拟南芥中有 5 个钙依赖蛋白激酶 (CDPK)CPK3、CPK4、CPK6、CPK10和CPK11参 与了 $A B A$ 诱导的气孔关闭过程, 其下游信号组分包括 
$\mathrm{Ca}^{2+}$ 内流、 $\mathrm{pH}$ 值变化、 $\mathrm{ROS}$ 产生、内向及外向 $\mathrm{K}^{+}$通 道活性改变以及慢速阴离子通道SLAC1激活等(Zou et al., 2010; Munemasa et al., 2011)。大量研究表明, $A B A$ 和JA在诱导气孔关闭中存在信号交叉与共享, 但目前只发现CPK6参与MeJA诱导的气孔关闭，而 其余4个CDPK在MeJA诱导的气孔关闭中似乎不起 作用(Munemasa et al., 2011)。这些结果表明, 尽管 $J A$ 与 $A B A$ 的信号途径在多个中间成分上存在交叉共 享, 但两者在调节气孔运动的信号细节上仍存在某些 特异性。有趣的是, 最近研究发现, 用ABA合成抑制 剂预处理野生型拟南芥可抑制MeJA 诱导的气孔关 闭。另外, ABA合成缺失突变体aba2-2也可阻断MeJA 诱导的气孔关闭, 而且MeJA可诱导ABA合成的关键 基因 NECD3表达上调。这些结果初步暗示了MeJA可 能通过诱导内源ABA水平升高而使气孔关闭(Hossain et al., 2011)。但ABA是否作为MeJA的下游信号 并介导其诱导的气孔关闭还需要更多的研究证据。综 上所述, MeJA/JA与ABA在诱导气孔关闭中的相互关 系还需深入研究。

如上所述, ABA、乙烯、JA和SA都通过增加ROS 的产生而诱导气孔关闭。那么, 另外2种植物激素 ——细胞分裂素(cytokinin)和生长素(auxin)通过降低 ROS水平而促进气孔张开就不难理解了。细胞分裂素 和生长素不仅参与植物的生长发育, 而且还可促使气 孔张开。最近人们对其促使气孔张开的机制也有所了 解。尽管这2种激素都可通过抑制 $\mathrm{H}_{2} \mathrm{O}_{2}$ 产生而阻止暗 诱导的气孔关闭, 但只有细胞分裂素可使已被暗处理 关闭的气孔重新开放, 这一作用通过降低暗处理中积 累的 $\mathrm{H}_{2} \mathrm{O}_{2}$ 而实现(Song et al., 2006)。此外还发现, 细 胞分裂素可抑制 $\mathrm{H}_{2} \mathrm{O}_{2}$ 诱导的保卫细胞内二氯荧光素 的荧光增强和气孔关闭, 生长素则无此作用。这暗示 了细胞分裂素可在ROS产生后启动 $\mathrm{H}_{2} \mathrm{O}_{2}$ 的清除机制, 而生长素只能在ROS产生的上游起作用(Song et al., 2006)。有趣的是, Tanaka等(2006)报道细胞分裂素 和生长素通过乙烯来抑制ABA诱导的气孔关闭。总之, 关于 $\mathrm{H}_{2} \mathrm{O}_{2}$ 在气孔内激素信号相互交叉对话中的作用 机制还有待后续的大量研究。

\section{2 非生物胁迫}

植物生长于室外经常遭遇多种环境胁迫刺激, 如光/ 暗变化、干旱、UV辐射、臭氧以及 $\mathrm{CO}_{2}$ 水平升高等。
这些胁迫刺激均会诱导植物体内 $R O S$ 水平升高并调 控气孔运动。

如前所述, 气孔在光合作用气体交换中发挥重要 作用。植物必须在光合作用 $\mathrm{CO}_{2}$ 吸收与蒸发作用水分 散失之间保持动态平衡。气孔在光下进行光合作用时 张开, 而在黑暗中关闭。室外条件下, 调控气孔运动 的环境刺激常常同时发生, 如光照与干旱常同时存 在, 气孔如何应对这些复合的环境刺激? 蓝光是自然 光的组分之一, 可通过磷酸化质膜 $\mathrm{H}^{+}$-ATPase的C末 端激活 $\mathrm{H}^{+}$-ATPase, 驱动细胞超极化, $\mathrm{K}^{+}$在保卫细胞 内积累, 气孔张开(Schroeder et al., 2001)。蓝光诱导 的气孔开放可被ABA抑制 (Leung and Giraudat, 1998)。 $\mathrm{H}_{2} \mathrm{O}_{2}$ 和 NO参与ABA抑制蓝光促进的气孔开放 过程, 它们可阻止蓝光依赖的质膜 $\mathrm{H}^{+}-A T P a s e$ 的磷酸 化与激活(Zhang et al., 2004, 2007)。因而, ABA信号 可抑制蓝光信号并调控气孔开闭。

与蓝光一样, UV-B同样是自然光的组分, 并可造 成植物的代谢和生理过程受伤害。UV-B辐射也可影 响气孔行为, 但引起气孔张开还是关闭取决于保卫细 胞的代谢状态(Jansen and van der Noort, 2000)。在 UV-B诱导虫豆气孔关闭中, 同时依赖于 $\mathrm{H}_{2} \mathrm{O}_{2}$ 和 NO 信号, 由于 $\mathrm{H}_{2} \mathrm{O}_{2}$ 和 NO可以相互促进对方的合成并形 成信号的反馈放大, 暗示了 $\mathrm{H}_{2} \mathrm{O}_{2}$ 和NO信号途径存在 相互交叉(He et al., 2005)。He等(2011)进一步发现, 干扰虫豆乙烯合成和乙烯信号途径可抑制UV-B辐射 诱导的 $\mathrm{H}_{2} \mathrm{O}_{2}$ 产生和气孔关闭。同时在研究UV-B诱导 的 $\mathrm{H}_{2} \mathrm{O}_{2}$ 产生来源时发现, 过氧化物酶抑制剂可阻断 UV-B诱导的 $\mathrm{H}_{2} \mathrm{O}_{2}$ 产生, 而 $\mathrm{NADPH}$ 氧化酶抑制剂则 不影响UV-B诱导的 $\mathrm{H}_{2} \mathrm{O}_{2}$ 产生。这些结果表明UV-B辐 射首先诱导乙烯合成, 进而乙烯通过刺激过氧化物酶 产生 $\mathrm{H}_{2} \mathrm{O}_{2}$, 最终诱导气孔关闭。

$\mathrm{CO}_{2}$ 对气孔行为的影响似乎依赖于 $\mathrm{CO}_{2}$ 浓度, 低 浓度 $\mathrm{CO}_{2}$ 诱导气孔张开; 而高浓度 $\mathrm{CO}_{2}$ 诱导气孔关闭, 但其中的原因还不清楚(Kolla et al., 2007)。在拟南芥 中, 使用重碳酸盐作为 $\mathrm{CO}_{2}$ 供体的高浓度 $\mathrm{CO}_{2}$ 诱导气 孔关闭实验中, $\mathrm{CO}_{2}$ 的作用与 $\mathrm{ABA}$ 类似, 其诱导气孔 关闭依赖于质膜上AtrbohD/F产生的 $\mathrm{H}_{2} \mathrm{O}_{2}$ (Kolla et al., 2007)。但 $\mathrm{CO}_{2}$ 诱导的气孔关闭又与ABA存在差异, $\mathrm{CO}_{2}$ 诱导的 $\mathrm{H}_{2} \mathrm{O}_{2}$ 产生慢且浓度低, 因而诱导的气孔 关闭作用稍弱(Kolla et al., 2007)。此外, 与ABA不同, $\mathrm{CO}_{2}$ 诱导的气孔关闭不存在胞质碱化现象, 但存在胞 
质 $\mathrm{Ca}^{2+}$ 水平升高现象。这些结果又印证了植物在应对 不同刺激时ROS及其下游信号的复杂性和细微差异 (Vavasseur and Raghavendra, 2005; Kolla et al., 2007)。

大气 $\mathrm{O}_{3}$ 污染可造成细胞伤害, 并引起与病原菌 侵染类似的二次氧化猝发现象(Joo et al., 2005)。在 拟南芥保卫细胞中, $\mathrm{O}_{3}$ 引起的ROS产生依赖于叶绿 体并可通过激活AtrbohD和AtrbohF将信号扩散至邻 近的表皮细胞(Joo et al., 2005)。 $\mathrm{O}_{3}$ 还可通过抑制 $\mathrm{K}^{+}$ 通道导致气孔关闭而减少 $\mathrm{CO}_{2}$ 的吸收(Torsethaugen et al., 1999)。对 O $_{3}$ 敏感的阴离子通道对ROS也敏感, 因而, $\mathrm{O}_{3}$ 对气孔开放的抑制效应似乎是通过ROS信 号而起作用(Vahisalu et al., 2008)。最近研究发现, $\mathrm{O}_{3}$ 诱导拟南芥气孔关闭伴随着ROS产生, 且在该信 号途径中发现SLAC1与OST1直接互作并被OST1磷 酸化激活(Vahisalu et al., 2010)。

暗诱导的气孔关闭中同样需要 $\mathrm{H}_{2} \mathrm{O}_{2}$ 的参与。 $\mathrm{H}_{2} \mathrm{O}_{2}$ 诱导的气孔关闭与 $A B A$ 诱导的气孔关闭的早期 事件存在许多相似性, 包括质膜 $\mathrm{H}^{+}$-ATPase失活、胞 质 $\mathrm{pH}$ 值升高和 $\mathrm{K}^{+}$外流等(Desikan et al., 2004)。由于 $\mathrm{H}_{2} \mathrm{O}_{2}$ 作为 $A B A$ 诱导气孔关闭的下游信号起作用, 用 NOX抑制剂二甲苯基碘 (dephenylene iodonium, $D P I)$ 、过氧化氢酶以及抗氧化剂 N-乙酰-半胱氨酸 ( $\mathrm{N}$-acetyl cysteine, NAC)均可抑制暗诱导的 $\mathrm{H}_{2} \mathrm{O}_{2}$ 产 生和气孔关闭。这暗示了 $A B A$ 和暗诱导的气孔关闭可 能在 $\mathrm{H}_{2} \mathrm{O}_{2}$ 这个节点上存在信号交叉共享(Desikan et al., 2004)。

\section{3 生物刺激}

植物早期应答病原菌或激发子时产生的氧化猝发作 为植物免疫反应的一部分起作用。氧化猝发反应不仅 可抵御病菌侵染, 还作为信号分子启动植物的抗性反 应。此后的抗性反应包括基因表达调节引起超敏反 应、诱导局部程序性细胞死亡及限制病原菌扩散。

据报道, 植物在遭受不同生物刺激时可通过多种 途径产生ROS。在烟草表皮细胞中发现一种真菌激发 子隐地蛋白(cryptogein)刺激产生的ROS, 其来源于 保卫细胞叶绿体; 而腐胺等多胺触发的ROS产生来 源于质外体。进一步利用ROS产生的酶抑制剂的研究 表明, 隐地蛋白诱导产生的ROS来源于黄素氧化酶, 腐胺诱导产生的ROS则来源于过氧化物酶或胺氧化
酶(Alllan and Fluhr, 1997)。此后有报道显示, 烟草 BY-2细胞中NOX和铜胺氧化酶分别参与隐地蛋白和 腐胺诱导的ROS产生(Kadota et al., 2004; An et al., 2008)。

传统概念认为叶片表面的气孔为病原菌侵染提 供了天然入口。而也有观点对这种概念提出质疑, 当 拟南芥受到细菌或细菌激发子攻击时, 其气孔可主动 关闭(Melotto et al., 2006)。Melotto等(2006)还将气 孔主动关闭与 $A B A$ 联系起来, 认为 $A B A$ 的下游信号组 分OST1和NO也参与病原菌侵染诱导的气孔主动关 闭过程。最近研究发现酵母激发子可诱导拟南芥保卫 细胞产生ROS和NO, 并通过胞质 $\mathrm{Ca}^{2+}$ 振荡诱导气孔 关闭。该过程中ROS来源于过氧化物酶, 而非质膜 $\mathrm{NADPH}$ 氧化酶(Khokon et al., 2010a)。但激发子诱 导的气孔关闭是否与OST1等ABA的下游信号组分有 关还有待进一步研究。

早在1999年, Lee等(1999)在研究某些植物-真菌 互作中就初步证明了 $\mathrm{H}_{2} \mathrm{O}_{2}$ 在其中的作用, 他们在番 茄(Lycopersicon esculentum)和鸭跖草中发现, 植物 细胞壁的一种降解产物臭聚半乳糖醛酸 (oligogalacturonic acid, OGA)和真菌细胞壁的一种组分几丁质 可诱导保卫细胞产生 $\mathrm{H}_{2} \mathrm{O}_{2}$ 并关闭气孔(Lee et al., 1999)。除了诱导气孔关闭外, OGA还可抑制气孔开 放。研究显示, 外源过氧化氢酶或抗坏血酸可抑制激 发子诱导的气孔关闭。这一结果暗示了 $\mathrm{H}_{2} \mathrm{O}_{2}$ 对于激发 子诱导的气孔关闭是必需的。但遗憾的是, 这些研究 仅仅观察了真菌细胞壁组分几丁质和植物细胞壁组 分OGA对气孔的影响, 而没有研究气孔应对真菌侵 染时的真实情况。最近发现几丁质可诱导拟南芥野生 型及atrbohd和atrbohf突变体保卫细胞产生ROS及气 孔关闭。然而, 过氧化物酶抑制剂可阻断几丁质诱导 的ROS产生及气孔关闭作用，表明几丁质诱导的 ROS产生来源于过氧化物酶而不是质膜 $N A D P H$ 氧化 酶(Khokon et al., 2010b)。对踠豆(Pisum sativum) 的研究显示, 与ABA和 JA的作用类似, 在几丁质诱导 的气孔关闭中, NO位于ROS的下游起作用, 并且质 膜 $\mathrm{Ca}^{2+}$ 通道也参与这一过程。表明几丁质与 $A B A$ 和 $J A$ 在诱导气孔关闭中共享信号转导途径(Srivastava et al., 2009)。进一步研究表明, 几丁质诱导的气孔关闭 过程可被MAPKK抑制剂PD98059阻断, 而且几丁质 不能诱导 $m p k 9 / m p k 12$ 双突变体的气孔关闭。该双突 
变体不受几丁质诱导而产生ROS、胞质碱化及胞质 $\mathrm{Ca}^{2+}$ 振荡, 但 $m p k 9$ 和 $m p k 12$ 单突变体的气孔行为与 野生型相同。这些结果表明MPK9和MPK12参与几丁 质诱导的气孔关闭过程, 且可能位于ROS产生的上 游(Salam et al., 2012)。

在真菌与气孔的互作中, 人们也发现有相反的结 果, 如死体营养型真菌大豆菌核病(Sclerotina sclerotiorum) 可诱导气孔张开, 然后菌丝可通过气孔侵染 叶片。这种真菌对气孔的操控依赖于毒性因子草酸, 草酸可能干扰 $\mathrm{H}_{2} \mathrm{O}_{2}$ 的产生而抑制ABA诱导的气孔关 闭(Guimarães and Stotz, 2004)。人们发现AtrbohD 和AtrbohF也参与病原菌侵染诱导的植物氧化猝发过 程(Torres et al., 2002)。由于草酸可抑制激发子诱导 的 $\mathrm{H}_{2} \mathrm{O}_{2}$ 产生(Cessna et al., 2000), 因而推测草酸在 植物-病原菌互作中也可能通过抑制质膜NOX而阻断 ROS产生并干扰气孔关闭。总之, ROS不仅参与生物 胁迫诱导的气孔关闭过程, 而且还可抑制气孔开放 (Desikan et al., 2004; Mishra et al., 2006; Yan et al., 2007)。对于植物应答病原菌侵染还有许多令人感兴 趣的问题值得深入探讨。

\section{ROS的产生与作用的调节}

\subsection{ROS产生的上游调节}

拟南芥OST1(open stomata 1)Ser/Thr蛋白激酶是较 早得到鉴定的参与ABA信号途径的蛋白激酶。该蛋白 激酶是从干旱胁迫诱导气孔关闭的突变体中鉴定出 来的。OST1基因编码SNF1相关的蛋白激酶(SnRK), 因此也被称为SnRK2E(Mustilli et al., 2002; Yoshida et al., 2002)。OST1基因在保卫细胞和维管系统中表 达, 并且其表达水平和激酶活性均受ABA诱导和激 活。ost1突变体特异地阻断ABA诱导的气孔关闭和 $A B A$ 抑制的气孔开放, 导致水分过度散失和干旱条件 下萎蒸表型, 表明OST1是ABA信号的正调控因子 (Mustilli et al., 2002; Yoshida et al., 2002)。ABA不 能诱导ost1突变体产生ROS, 外源 $\mathrm{H}_{2} \mathrm{O}_{2}$ 可使ost1突 变体气孔关闭, 说明OST1蛋白激酶介导了ABA诱导 的保卫细胞产生ROS。而且, 已有直接证据表明 OST1 可直接与 AtrbohF互作, 磷酸化 AtrbohF 的 Ser12和Ser174使其激活并产生ROS(Sirichandra et al., 2009)。这从分子机制上解释了ABA诱导保卫细胞
产生ROS的途径之一。此外, OST1的C末端包含功能 结构域I和II(Yoshida et al., 2006), 其中结构域I不参 与ABA诱导的OST1激活; 而结构域II可与ABA信号 的重要负调控因子PP2C磷酸酶ABI1互作(Yoshida et al., 2006)。这种互作导致OST1激酶活性受ABI1的抑 制。此前有报道显示ABI1可阻断ABA诱导的 $\mathrm{H}_{2} \mathrm{O}_{2}$ 产 生(Murata et al., 2001)。因而, ABI1可能正是通过抑 制OST1激酶活性而抑制ABA诱导的 $\mathrm{H}_{2} \mathrm{O}_{2}$ 产生。

ABA和JA诱导ROS产生时均存在胞质碱化现象 (Suhita et al., 2004; Islam et al., 2010)。保卫细胞中 $\mathrm{pH}$ 值变化与ROS积累的动态过程显示胞质碱化先于 ROS产生(Gonugunta et al., 2008)。有趣的是, ABA 并不能诱导ost1突变体产生ROS及气孔关闭, 而JA 却可以。与此类似, JA不能诱导jar1-1突变体产生 ROS及气孔关闭, 而ABA却可以 (Suhita et al., 2004)。这些结果暗示ABA和JA可能通过完全不同的 途径诱导产生ROS。

最近研究表明, 异三聚体 $\mathrm{G}$ 蛋白的 $\alpha$ 亚单位缺失 突变体阻断了ABA诱导的ROS产生及 $\mathrm{Ca}^{2+}$ 通道激活。 而外源 $\mathrm{H}_{2} \mathrm{O}_{2}$ 可正常诱导gpa1突变体气孔关闭并抑制 其气孔开放, 该突变体的 $\mathrm{Ca}^{2+}$ 通道也可被 $\mathrm{H}_{2} \mathrm{O}_{2}$ 正常 激活。另外, 该突变体还同时阻断了 $A B A$ 抑制的内向 $\mathrm{K}^{+}$电流和不依赖于 $\mathrm{pH}$ 值的外向阴离子电流。这些结 果表明, GPA1在ABA诱导气孔关闭中位于ROS产生 的上游(Zhang et al., 2011)。研究表明, 异三聚体G 蛋白参与植物应答 $\mathrm{O}_{3}$ 胁迫时的 ROS产生过程, $\mathrm{Ga}$ 和 $G \beta$ 亚基对源于叶绿体的第1相氧化猝发是必需的。然 而, 源于包括质膜 $\mathrm{RBOH}$ 在内的多途径的第2相氧化 猝发过程仅需要Ga亚基的参与(Joo et al., 2005)。

\subsection{ROS作用的下游调节}

如前所述, 决定气孔开度的重要因素是保卫细胞中离 子的浓度。众多证据表明, ROS在ABA(或非ABA)调 节的保卫细胞离子浓度变化中起重要作用。Pei等 (2000)的研究表明, 在 $\mathrm{H}_{2} \mathrm{O}_{2}$ 介导 $A B A$ 诱导的气孔关 闭中, $\mathrm{H}_{2} \mathrm{O}_{2}$ 可激活质膜 $\mathrm{Ca}^{2+}$ 通道, 引起 $\mathrm{Ca}^{2+}$ 内流, 最 终导致气孔关闭。Kwak等(2003)发现, 在atrbohdlf 双突变体保卫细胞中, $A B A$ 诱导的胞质 $\mathrm{Ca}^{2+}$ 浓度升高 幅度明显小于野生型。而且, 外源 $\mathrm{H}_{2} \mathrm{O}_{2}$ 可正常激活 atrbohdlf双突变体的 $\mathrm{Ca}^{2+}$ 透过性通道 $\left(\mathrm{I}_{\mathrm{Ca}}\right)$, 表明来源 于质膜 $\mathrm{RBOH}$ 产生的 $\mathrm{H}_{2} \mathrm{O}_{2}$ 激活了质膜 $\mathrm{Ca}^{2+}$ 通道并介 
导了 $A B A$ 信号。然而也有报道显示在诱导气孔关闭中 $\mathrm{H}_{2} \mathrm{O}_{2}$ 的作用可能与ABA不同(Köhler et al., 2003)。利 用电压钳技术对蚕豆保卫细胞的研究结果表明, 外向 $\mathrm{K}^{+}$通道 $\left(\mathrm{K}_{\text {out }}^{+}\right)$对于 $A B A$ 和 $\mathrm{H}_{2} \mathrm{O}_{2}$ 的反应不同, $A B A$ 以可 逆的方式抑制内向 $\mathrm{K}^{+}$通道 $\left(\mathrm{K}^{+}{ }_{\mathrm{in}}\right), 1-50 \mu \mathrm{mol} \cdot \mathrm{L}^{-1} \mathrm{H}_{2} \mathrm{O}_{2}$ 则以不可逆的方式同时抑制 $\mathrm{K}^{+}{ }_{\text {in }}$ 和 $\mathrm{K}^{+}{ }_{\text {out }}$ 。这暗示了与 ABA 诱导产生的 $\mathrm{H}_{2} \mathrm{O}_{2}$ 不同, 其它刺激诱导产生的 $\mathrm{H}_{2} \mathrm{O}_{2}$ 可能作用于 $\mathrm{K}^{+}$out。然而, 也不能排除外源施加 $\mathrm{H}_{2} \mathrm{O}_{2}$ 与保卫细胞产生或释放的 $\mathrm{H}_{2} \mathrm{O}_{2}$ 具有不同作用方 式的可能性。推测 $\mathrm{H}_{2} \mathrm{O}_{2}$ 并非作为 $A B A$ 信号途径的中间 组分, 而是 $\mathrm{H}_{2} \mathrm{O}_{2}$ 信号和 $A B A$ 信号在激活 $\mathrm{Ca}^{2+}$ 通道这 一节点上存在交叠。尽管在外向 $\mathrm{K}^{+}$通道突变体 gork1 中, JA通过ROS诱导的气孔关闭受到影响, 但对于 $\mathrm{H}_{2} \mathrm{O}_{2}$ 调节的 $\mathrm{K}^{+}$通道与 $A B A$ 调节的 $\mathrm{K}^{+}$通道是否相同还 不得而知(Suhita et al., 2004)。另外一个支持 $\mathrm{H}_{2} \mathrm{O}_{2}$ 和 $A B A$ 不同作用机理的实验证据如下: 用 $\mathrm{H}_{2} \mathrm{O}_{2}$ 处理拟 南芥中一种V-ATPase突变体det3时, 其 $\left[\mathrm{Ca}^{2+}\right]_{\mathrm{cyt}}$ 振荡 和气孔关闭受阻, 而ABA却能正常诱导 $d e t 3$ 突变体 $\left[\mathrm{Ca}^{2+}\right]_{\mathrm{cyt}}$ 振荡和气孔关闭。这一结果提示在保卫细胞 中, 不同的刺激具有不同的信号途径(Allen et al., 2000)。

如前文所述, $\mathrm{Cl}^{-}$通过快速 $(\mathrm{R}$ 型)和慢速 $(\mathrm{S}$ 型)阴离 子通道外流, 进而引起 $\mathrm{K}^{+}$外流, 保卫细胞膨压下降, 最终导致气孔关闭。直到最近, 控制离子进出的通道 膜蛋白才得以鉴定。其中 SLAC1编码一种慢速阴离子 通道, 用 $\mathrm{O}_{3} 、 \mathrm{CO}_{2}$ 、光/暗周期变化、 $\mathrm{H}_{2} \mathrm{O}_{2} 、 \mathrm{NO} 、 \mathrm{Ca}^{2+}$ 和ABA处理时, slac1突变体表现出慢速阴离子电流 缺失和气孔无法关闭的表型(Negi et al., 2008; Vahisalu et al., 2008)。最新报道显示, 拟南芥保卫细胞 中快速阴离子通道QUAC1也受OST1的激活而介导 ABA诱导的气孔关闭过程。在abi1-1和ost1-2突变体 中ABA激活的QUAC1通道受阻(Imes et al., 2013)。

与 $A B I 1$ 类似, 另一个PP2C类磷酸酶ABI2同样作 为 $A B A$ 信号的负调控因子起作用。abi1-1突变体阻断 了ABA诱导的ROS产生与气孔关闭, 因而ABI1位于 $\mathrm{ROS}$ 产生的上游。而在abi2-1突变体中阻断了 $\mathrm{H}_{2} \mathrm{O}_{2}$ 激活的 $\mathrm{Ca}^{2+}$ 通道和气孔关闭, 但ABA可正常诱导该突 变体产生ROS, 表明ABI2 位于ROS的下游起作用 (Murata et al., 2001)。

除了蛋白磷酸酶ABI1和 $A B I 2$ 外, MAP激酶MPK3 也参与 $A B A$ 和 $\mathrm{H}_{2} \mathrm{O}_{2}$ 诱导的气孔关闭以及 $\mathrm{H}_{2} \mathrm{O}_{2}$ 抑制的
气孔开放(Gudesblat et al., 2006)。在MPK3沉默的转 基因植物中, $A B A$ 诱导的 $\mathrm{H}_{2} \mathrm{O}_{2}$ 产生不受影响, 表明 $M P K 3$ 位于 $\mathrm{H}_{2} \mathrm{O}_{2}$ 的下游参与 $A B A$ 诱导的气孔关闭过 程(Gudesblat et al., 2006)。

乙烯受体ETR1是一种双组分组蛋白激酶, 具有 感受外界刺激和转导信号的功能(Grefen and Harter, 2004)。ETR1受体在保卫细胞中表达并含有3个结构 域, 即 $\mathrm{N}$ 端信号输入结构域、中间信号传递结构域和 C 端信号接受结构域。信号输入结构域感受外界刺激并 启动开始于组蛋白激酶结构域内的保守组氨酸的一 系列磷酸转移反应, 磷酸基团被传递到位于信号接受 结构域中保守的天冬氨酸残基上, 此后进一步被传递 到反应调节元件内保守的天冬氨酸, 最终引发一系列 细胞反应(Hwang et al., 2002; Grefen and Harter, 2004; Desikan et al., 2005b)。Desikan等(2005b)的 研究表明ETR1的N-端信号输入结构域中的Cys65对 于 $\mathrm{H}_{2} \mathrm{O}_{2}$ 诱导的气孔关闭至关重要。当etr1-1突变体中 发生Cys-65-Tyr氨基酸替换时, 该突变体对 $\mathrm{H}_{2} \mathrm{O}_{2}$ 诱 导的气孔关闭不敏感, 而突变体 etr1-3中发生 Ala-31-Val氨基酸替换时, 并不影响 $\mathrm{H}_{2} \mathrm{O}_{2}$ 诱导的气孔 关闭, 说明Cys65对于保卫细胞的 $\mathrm{H}_{2} \mathrm{O}_{2}$ 反应是必需 的。尽管ETR1的下游调节元件ARR2参与 $\mathrm{H}_{2} \mathrm{O}_{2}$ 诱导 的气孔关闭, 但ETR1本身的组蛋白激酶活性对于 $\mathrm{H}_{2} \mathrm{O}_{2}$ 诱导的气孔关闭并非必需 (Desikan et al., 2006)。通过双组分系统对 $\mathrm{H}_{2} \mathrm{O}_{2}$ 信号感受和传递的分 子机制还有待进一步研究。

\subsection{ROS产生与作用的细胞内区室化调节}

如上所述, 定位于保卫细胞中不同位置的多种酶均可 产生 $\mathrm{H}_{2} \mathrm{O}_{2}$ 。例如, $\mathrm{RBOH}$ 定位于质膜; 过氧化物酶定 位于质外体和细胞壁; 黄嘌呤氧化酶定位于过氧化物 酶体。ROS作用的下游靶蛋白同样定位于不同的细胞 器。如 $A B I 1 / A B I 2$ 定位于细胞质; ETR1定位于内质网; SALC1、 $\mathrm{K}^{+}$通道蛋白和 $\mathrm{Ca}^{2+}$ 通道蛋白定位于质膜。显 而易见, 这些ROS产生途径间必须精密协调, 并按植 物的生理需求在适当的细胞区室内控制ROS的产生 及其作用。

$\mathrm{H}_{2} \mathrm{O}_{2}$ 作为细胞内信号分子其自身可以在细胞间 扩散。前期研究表明, 将表皮细胞暴露在白光下, 不 仅可在暴露的细胞中诱导产生ROS, 而且还可以在 邻近的未暴露的保卫细胞中诱导产生ROS。由于保卫 
细胞与周围的表皮细胞间并不存在共质体直接连接, 因而 $\mathrm{H}_{2} \mathrm{O}_{2}$ 可能作为信号分子通过质外体或跨越细胞 质膜在细胞间扩散(Allan and Fluhr, 1997)。研究还发 现 $\mathrm{O}_{3}$ 诱导的叶绿体ROS产生对于表皮细胞间ROS信 号传播是必需的, 但这种ROS信号不在保卫细胞间 传播(Joo et al., 2005)。最近发现 $\mathrm{H}_{2} \mathrm{O}_{2}$ 可通过2个来源 于拟南芥的水通道蛋白 TIP1;1和TIP1;2跨越细胞膜 进行扩散(Biernet et al., 2007)。遗憾的是, 这一结果 是在酵母细胞中发现的。这 2 个水通道蛋白在植物细 胞中是否具有同样的功能还不确定。这 2 个基因的缺 失突变体是否影响ROS信号的传播将为回答这一问 题提供依据。

总之, 在亚细胞水平上对各种生物或非生物刺激 产生的 $\mathrm{H}_{2} \mathrm{O}_{2}$ 进行定位, 对于理解保卫细胞内 $\mathrm{H}_{2} \mathrm{O}_{2}$ 产 生的细胞内区室化调节尤为重要。

\section{ROS的清除}

ROS清除剂除了具备解除ROS毒性的基本功能外, 也参与ROS信号的精细调控(Mittler, 2002)。因而, ROS信号过程必然存在ROS产生及其浓度的区室控 制以及ROS清除三者间的精巧平衡, 其中ROS清除 过程包括细胞内抗氧化剂、ROS清除酶类以及氧化还 原状态调节等。

超氧化物歧化酶(superoxide dismutase, SOD) 可将 $\mathrm{O}_{2}{ }^{-}$歧化为 $\mathrm{H}_{2} \mathrm{O}_{2}, \mathrm{H}_{2} \mathrm{O}_{2}$ 进一步被过氧化氢酶 (catalase, CAT)、抗坏血酸过氧化物酶(ascorbate peroxidase, APX)、谷脱甘肽过氧化物酶(glutathione peroxidase, GPX)等分解, 后两者分别需要还原型抗 坏血酸 (ascorbic acid, Asc)和谷胱甘肽 (glutataione, GSH) 作为还原剂 (Mittler, 2002; Apel and Hirt, 2004)。而Asc和GSH水平的维持又需要谷胱甘肽还 原酶(glutathione reductase, GR)、单脱氢抗坏血酸还 原酶(monodehydroascorbate reductase, MDAR)以 及脱氢抗坏血酸还原酶 (dehydroascorbate reductase, DHAR)的参与(Mittler, 2002; Apel and Hirt, 2004)。通常认为, ROS清除能力缺陷和细胞内氧化还 原状态失衡都会影响细胞内ROS的水平和ROS调控 的植物生理反应。然而, 也有相反的研究报道。拟南 芥GSH合成缺陷突变体ch1-1表现出ABA诱导的气孔 关闭作用比野生型增强, 但ROS水平末受影响。同时,
$A B A$ 抑制的气孔张开过程不受GSH含量降低的影响。 这一结果暗示GSH或许位于ROS的下游而参与 $A B A$ 诱导的气孔关闭(Jahan et al., 2008)。在拟南芥中进 行药理学处理使保卫细胞中GSH含量降低, 不影响 保卫细胞中ROS的含量、胞质碱化和胞质 $\mathrm{Ca}^{2+}$ 振荡, 但会增强 $A B A$ 和 JA诱导的气孔关闭 (Akter et al., 2012)。总之, GSH与ROS的上下游关系还需进一步 确认。

Asc 是植物细胞内含量最丰富的抗氧化剂之一, Asc除了清除ROS外, 其本身也可能参与保卫细胞的 ROS信号过程。人们发现烟草中 $\mathrm{H}_{2} \mathrm{O}_{2}$ 的含量和Asc的 氧化还原状态随昼夜周期而变化, $\mathrm{H}_{2} \mathrm{O}_{2}$ 水平的最高峰 出现在午后, 并伴随着气孔关闭, 而在早晨、傍晚和 夜里较低。Asc的氧化还原状态则与 $\mathrm{H}_{2} \mathrm{O}_{2}$ 水平的变化 正好相反, 暗示两者间存在某种联系。APX1基因的 缺失突变体不能对光/暗周期变化作出响应, 而且其 叶片中含有比野生型更高的 $\mathrm{H}_{2} \mathrm{O}_{2}$ 水平, 进一步暗示 了APX和Asc之间的联系对气孔行为的调控(Pnueli et al., 2003)。研究表明Asc氧化还原状态可影响气孔 反应, 过表达DHAR可导致Asc氧化还原状态升高, 降低 $\mathrm{H}_{2} \mathrm{O}_{2}$ 水平并削弱 $A B A$ 和 $\mathrm{H}_{2} \mathrm{O}_{2}$ 诱导的气孔关闭 (Chen and Gallie, 2004)。由于过表达DHAR可提高 DHA水平, 并有利于DHA向Asc的转化, 而不是提高 Asc本身, 这暗示了Asc氧化还原状态本身(也就是 Asc 和DHA之间的平衡)对气孔行为的重要性(Chen and Gallie, 2004)。

拟南芥ATGPX3 基因在保卫细胞中强烈表达, atgpx3突变体对 $A B A$ 和 $\mathrm{H}_{2} \mathrm{O}_{2}$ 不敏感, 暗示ATGPX3 可能作为桥梁连接了 $\mathrm{H}_{2} \mathrm{O}_{2}$ 和 $A B A$ 诱导气孔关闭的下 游事件。在酵母双杂交和GST pull-down实验中发现, ATGPX3 可与 $A B I 1$ 和 $A B I 2$ 互作并抑制其活性, 因而 削弱了 $A B I 1$ 和 $A B I 2$ 对 $A B A$ 信号的负调控作用, 导致 气孔关闭。 $\mathrm{H}_{2} \mathrm{O}_{2}$ 还调控了ATGPX3和ABI2的氧化还 原状态, 使两者结合得更紧密。atgpx3突变体中 $A B A$ 和 $\mathrm{H}_{2} \mathrm{O}_{2}$ 诱导的 $\mathrm{Ca}^{2+}$ 电流被削弱。暗示ATGPX3可感受 和转导 $\mathrm{H}_{2} \mathrm{O}_{2}$ 信号, 并与 $\mathrm{ABI}$ 互作启动 $\mathrm{Ca}^{2+}$ 内流, 最 终导致气孔关闭(Miao et al., 2006)。

\section{6 研究展望}

从人们第一次认识到ROS可调控气孔运动时起(McAinsh 


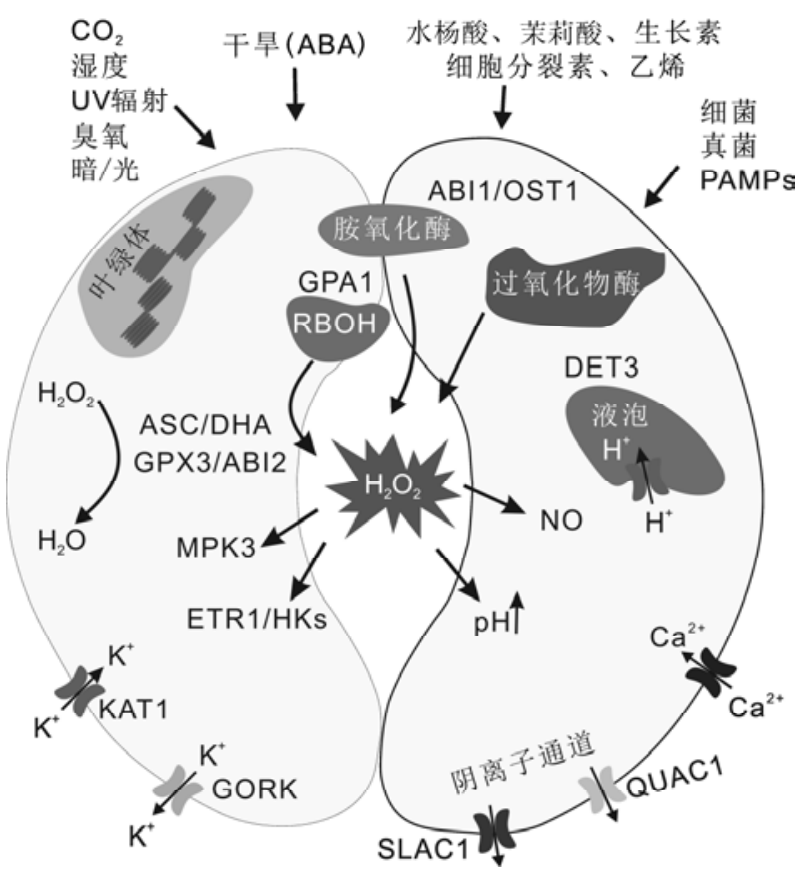

图1 气孔保卫细胞中的ROS信号(引自Pham and Desikan, 2009, 并做修改)

Figure 1 ROS signaling in guard cells (modified from Pham and Desikan, 2009)

et al., 1996), 对于气孔运动中的ROS信号的研究经 历了漫长的过程。图1总结了保卫细胞中的ROS信号。 一方面, 多种刺激分别通过不同的途径诱导保卫细胞 产生ROS; 另一方面, 保卫细胞中的抗氧化剂及氧化 还原信号在调控气孔行为中也发挥了重要作用。已鉴 定的一系列蛋白组分不仅调节ROS的产生, 而且调 控ROS信号的转导与传播, 保卫细胞不同区域内 ROS产生与清除的精确调控对于气孔的开闭反应至 关重要。然而, 对气孔运动中的ROS信号的研究不仅 揭示了一些表象, 而且为后人留下了许多问题。例如, 保卫细胞如何区分不同的刺激并通过特异的途径产 生ROS, 最终作出相应的生理反应。其中 $\mathrm{H}_{2} \mathrm{O}_{2}$ 特异感 受子和受体至今尚未确定。也就是说, 我们仍不确定 细胞如何感受 $\mathrm{H}_{2} \mathrm{O}_{2}$, 也不清楚在细胞感受 $\mathrm{H}_{2} \mathrm{O}_{2}$ 信号 转导过程中, 哪些细胞过程是最主要的或是限速步 骤。又如, 保卫细胞是否存在有别于其它细胞类型的 特异的ROS信号组分; 或者目前已知的参与保卫细 胞ROS的信号组分是否在其它类型细胞中也具有同 样的功能。气孔利用ROS整合多种环境刺激是一个令
人兴奋的研究领域。气孔如何通过灵敏的开闭运动帮 助植物更好地适应胁迫环境, 这一问题对于理解当前 多变的全球气候环境显得十分重要。鉴定不同植物物 种间共有的ROS信号关键组分对于农业育种和提高 作物耐(抗)性将大有裨益。若能在细胞水平绘制和预 测应对环境变化时细胞内的变化细节, 无疑将加速未 来的研究进程。

\section{参考文献}

侯智慧, 车永梅, 王兰香, 侯丽霞, 刘新 (2012). $\mathrm{H}_{2} \mathrm{~S}$ 位于 $\mathrm{H}_{2} \mathrm{O}_{2}$ 下游参与乙烯诱导拟南芥气孔关闭过程. 植物生理学 报 48, 1193-1199.

刘菁, 侯丽霞, 刘国华, 刘新, 王学臣 (2011). NO介导的 $\mathrm{H}_{2} \mathrm{~S}$ 合成参与乙烯诱导的拟南芥气孔关闭. 科学通报 56 , 2515-2522.

刘菁, 刘国华, 侯丽霞, 刘新 (2010). 胞质 $\mathrm{pH}$ 变化介导乙烯 诱导的拟南芥保卫细胞NO产生和气孔关闭. 科学通报 $\mathbf{5 5}$, 2003-2009.

苗雨晨, 宋纯鹏, 董发才, 王学臣 (2000). ABA诱导䖯豆气孔 保卫细胞 $\mathrm{H}_{2} \mathrm{O}_{2}$ 的产生. 植物生理学报 26, 53-58.

王兰香, 侯智慧, 侯丽霞, 赵方贵, 刘新 (2012). $\mathrm{H}_{2} \mathrm{O}_{2}$ 介导的 $\mathrm{H}_{2} \mathrm{~S}$ 产生参与干旱诱导的拟南芥气孔关闭. 植物学报 47 , 217-225.

Akter N, Sobahan MA, Uraji M, Ye WX, Hossain MA, Mori IC, Nakamura Y, Murata Y (2012). Effects of depletion of glutathione on abscisic acid- and methyl jasmonate-induced stomatal closure in Arabidopsis thaliana. Biosci Biotechnol Biochem 76, 2032-2037.

Allan AC, Fluhr R (1997). Two distinct sources of elicited reactive oxygen species in tobacco epidermal cells. Plant Cell 9, 1559-1572.

Allen GJ, Chu SP, Schumacher K, Shimazaki CT, Vafeados D, Kemper A, Hawke SD, Tallman G, Tsien RY, Harper JF, Chory J, Schroeder JI (2000). Alteration of stimulus-specific guard cell calcium oscillations and stomatal closing in Arabidopsis det3 mutant. Science 289, 2338-2342.

An ZF, Jing W, Liu YL, Zhang WH (2008). Hydrogen peroxide generated by copper amine oxidase is involved in abscisic acid-induced stomatal closure in Vicia faba. $\mathrm{J}$ Exp Bot 59, 815-825.

Apel K, Hirt H (2004). Reactive oxygen species: metabolism, oxidative stress, and signal transduction. Annu Rev 
Plant Biol 55, 373-399.

Beguerisse-Dıaz M, Hernández-Gómez MC, Lizzul AM, Barahona M, Desikan R (2012). Compound stress response in stomatal closure: a mathematical model of $A B A$ and ethylene interaction in guard cells. BMC Syst Biol 6 , 146.

Biernet GP, Møller ALB, Kristiansen KA, Schulz A, Møller IM, Schjoerring JK, Jahn TP (2007). Specific aquaporins facilitate the diffusion of hydrogen peroxide across membranes. J Biol Chem 282, 1183-1192.

Blatt MR (2000). Cellular signaling and volume control in stomatal movements in plants. Annu Rev Cell Dev Biol 16, 221-241.

Bolwell GP, Bindschedler LV, Blee KA, Butt VS, Davies DR, Gardner SL, Gerrish C, Minibayeva F (2002). The apoplastic oxidative burst in response to biotic stress in plants: a three-component system. J Exp Bot 53, 13671376.

Bright J, Desikan R, Hancock JT, Weir IS, Neill SJ (2006). ABA-induced NO generation and stomatal closure in Arabidopsis are dependent on $\mathrm{H}_{2} \mathrm{O}_{2}$ synthesis. Plant $\mathrm{J}$ 45, 113-122.

Cessna SG, Sears VE, Dickman MB, Low PS (2000). Oxalic acid, a pathogenicity factor for Sclerotinia sclerotiorum, suppresses the oxidative burst of the host plant. Plant Cell 12, 2191-2200.

Chen Z, Gallie DR (2004). The ascorbic acid redox state controls guard cell signaling and stomatal movement. Plant Cell 16, 1143-1162.

Cheng YL, Song CP (2006). Hydrogen peroxide homeostasis and signaling in plant cells. Sci China C Life Sci 49, $1-11$.

Daszkowska-Golec A, Szarejko I (2013). Open or close the gate-stomata action under the control of phytohormones in drought stress conditions. Front Plant Sci 4, 138.

del Río LA, Corpas FJ, Sandalio LM, Palma JM, Gómez M, Barroso JB (2002). Reactive oxygen species, antioxidant systems and nitric oxide in peroxisomes. $J$ Exp Bot 53, 1255-1272.

Desikan R, Cheung MK, Clarke A, Golding S, Sagi M, Fluhr R, Rock C, Hancock J, Neill S (2004). Hydrogen peroxide is a common signal for darkness- and ABAinduced stomatal closure in Pisum sativum. Funct Plant Biol 31, 913-920.

Desikan R, Hancock J, Neill S (2005a). Reactive oxygen species as signaling molecules. In: Antioxidants and Re- active Oxygen Species in Plants. Oxford: Blackwell. pp.169-196.

Desikan R, Hancock JT, Bright J, Harrison J, Weir I, Hooley R, Neill SJ (2005b). A role for ETR1 in hydrogen peroxide signaling in stomatal guard cells. Plant Physiol 137, 831-834.

Desikan R, Last K, Harrett-Williams R, Tagliavia C, Harter K, Hooley R, Hancock JT, Neill SJ (2006). Ethylene-induced stomatal closure in Arabidopsis occurs via AtrbohF-mediated hydrogen peroxide synthesis. Plant $\mathrm{J}$ 47, 907-916.

Gonugunta VK, Srivastava N, Puli MR, Raghavendra AS (2008). Nitric oxide production occurs after cytosolic alkalinization during stomatal closure induced by abscisic acid. Plant Cell Environ 31, 1717-1724.

Grefen C, Harter K (2004). Plant two-component systems: principles, functions, complexity and cross talk. Planta 219, 733-742.

Gudesblat GE, lusem ND, Morris PC (2006). Guard cell-specific inhibition of Arabidopsis MPK3 expression causes abnormal stomatal responses to abscisic acid and hydrogen peroxide. New Phytol 173, 713-721.

Guimarães RL, Stotz HU (2004). Oxalate production by Sclerotinia sclerotiorum deregulates guard cells during infection. Plant Physiol 136, 3703-3711.

Hao FS, Zhao SL, Dong H, Zhang H, Sun LR, Miao C (2010). Nia1 and Nia2 are involved in exogenous salicylic acid-induced nitric oxide generation and stomatal closure in Arabidopsis. J Integr Plant Biol 52, 298-307.

He JM, Xu H, She XP, Song XG, Zhao WM (2005). The role and the interrelationship of hydrogen peroxide and nitric oxide in the UV-B-induced stomatal closure in broad bean. Funct Plant Biol 32, 237-247.

He JM, Yue XZ, Wang RB, Zhang Y (2011). Ethylene mediates UV-B-induced stomatal closure via peroxidasedependent hydrogen peroxide synthesis in Vicia faba L. $J$ Exp Bot 62, 2657-2666.

Hossain MA, Munemasa S, Uraji M, Nakamura Y, Mori IC, Murata $Y$ (2011). Involvement of endogenous abscisic acid in methyl jasmonate-induced stomatal closure in Arabidopsis. Plant Physiol 156, 430-438.

Hwang I, Chen HC, Sheen J (2002). Two-component signal transduction pathways in Arabidopsis. Plant Physiol 129, 500-515.

Imes D, Mumm P, Böhm J, Al-Rasheid KAS, Marten I, Geiger D, Hedrich R (2013). Open stomata 1 (OST1) 
kinase controls R-type anion channel QUAC1 in Arabidopsis guard cells. Plant J 74, 372-382.

Islam MM, Hossain MA, Jannat R, Munemasa S, Nakamura Y, Mori IC, Murata Y (2010). Cytosolic alkalization and cytosolic calcium oscillation in Arabidopsis guard cells response to ABA and MeJA. Plant Cell Physiol 51, 1721-1730.

Jahan MS, Ogawa K, Nakamura Y, Shimoishi Y, Mori IC, Murata Y (2008). Deficient glutathione in guard cells facilitates abscisic acid-induced stomatal closure but does not affect light-induced stomatal opening. Biosci Biotechnol Biochem 72, 2795-2798.

Jansen MAK, van der Noort RE (2000). Ultraviolet-B radiation induces complex alterations in stomatal behaviour. Physiol Plant 110, 189-194.

Joo JH, Wang SY, Chen JG, Jones AM, Fedoroff NV (2005). Different signaling and cell death roles of heterotrimeric $G$ protein $\alpha$ and $\beta$ subunits in the Arabidopsis oxidative stress response to ozone. Plant Cell 17, 957-970.

Kadota Y, Goh T, Tomatsu H, Higashi K, Muto S, Kuchitsu K (2004). Cryptogein-induced initial events in tobacco BY-2 cells: pharmacological characterization of molecular relationship among cytosolic $\mathrm{Ca}^{2+}$ transients, anion efflux and production of reactive oxygen species. Plant Cell Physiol 45, 160-170.

Keller T, Damunde HG, Werner D, Doerner P, Dixon RA, Lamb C (1998). A plant homolog of the neutrophil NADPH oxidase gp91 ${ }^{\text {phox }}$ subunit gene encodes a plasma membrane protein with $\mathrm{Ca}^{2+}$ binding motifs. Plant Cell 10, 255-266.

Khokon AR, Hossain MA, Munemasa S, Uraji M, Nakamura Y, Mori IC, Murata Y (2010a). Yeast elicitor-induced stomatal closure and peroxidase-mediated ROS production in Arabidopsis. Plant Cell Physiol 51, 1915-1921.

Khokon AR, Okuma E, Hossain MA, Munemasa S, Uraji M, Nakamura Y, Mori IC, Murata Y (2011). Involvement of extracellular oxidative burst in salicylic acid-induced stomatal closure in Arabidopsis. Plant Cell Environ 34, 434-443.

Khokon AR, Uraji M, Munemasa S, Okuma E, Nakamura Y, Mori IC, Murata Y (2010b). Chitosan-induced stomatal closure accompanied by peroxidase-mediated reactive oxygen species production in Arabidopsis. Biosci Biotechnol Biochem 74, 2313-2315.
Köhler B, Hills A, Blatt MR (2003). Control of guard cell ion channels by hydrogen peroxide and abscisic acid indicates their action through alternate signaling pathways. Plant Physiol 131, 385-388.

Kolla VA, Vavasseur A, Raghavendra AS (2007). Hydrogen peroxide production is an early event during bicarbonate induced stomatal closure in abaxial epidermis of Arabidopsis. Planta 225, 1421-1429.

Kwak JM, Mori IC, Pei ZM, Leonhardt N, Torres MA, Dangl JL, Bloom RE, Bodde S, Jones JDG, Schroeder JI (2003). NADPH oxidase AtrbohD and AtrbohF genes function in ROS-dependent ABA signaling in Arabidopsis. EMBO J 22, 2623-2633.

Lee S, Choi H, Suh S, Doo IS, Oh KY, Choi EJ, Schroeder Taylor AT, Low PS, Lee Y (1999). Oligogalacturonic acid and chitosan reduce stomatal aperture by inducing the evolution of reactive oxygen species from guard cells of tomato and Commelina communis. Plant Physiol 121, 147-152.

Leung J, Giraudat J (1998). Abscisic acid signal transduction. Annu Rev Plant Physiol Plant Mol Biol 49, 199-222.

Levitt LK, Stein DB, Rubinstein B (1987). Promotion of stomatal opening by indoleacetic acid and ethrel in epidermal strips of Vicia faba L. Plant Physiol 85, 318-321.

Madhavan S, Chrominiski A, Smith BN (1983). Effect of ethylene on stomatal opening in tomato and carnation leaves. Plant Cell Physiol 24, 569-572.

McAinsh MR, Clayton H, Mansfield TA, Hetherington AM (1996). Changes in stomatal behavior and guard cell cytosolic free calcium in response to oxidative stress. Plant Physiol 111, 1031-1042.

Melotto M, Underwood W, Koczan J, Nomura K, He SY (2006). Plant stomata function in innate immunity against bacterial invasion. Cell 126, 969-980.

Merritt F, Kemper A, Tallman G (2001). Inhibitors of ethylene synthesis inhibit auxin-induced stomatal opening in epidermis detached from leaves of Vicia faba L. Plant Cell Physiol 42, 223-230.

Miao YC, Lü D, Wang PC, Wang XC, Chen J, Miao C, Song CP (2006). An Arabidopsis glutathione peroxidase functions as both a redox transducer and a scavenger in abscisic acid and drought stress responses. Plant Cell 18, 2749-2766.

Mishra G, Zhang WH, Deng F, Zhao J, Wang XM (2006). A bifurcating pathway directs abscisic acid effects on stomatal closure and opening in Arabidopsis. Science 
312, 264-266.

Mittler R (2002). Oxidative stress, antioxidants and stress tolerance. Trends Plant Sci 7, 405-410.

Mori IC, Pinontoan R, Kawano T, Muto S (2001). Involvement of superoxide generation in salicylic acid-induced stomatal closure in Vicia faba. Plant Cell Physiol 42, 1383-1388.

Munemasa S, Hossain MA, Nakamura Y, Mori IC, Murata Y (2011). The Arabidopsis calcium-dependent protein kinase, CPK6, functions as a positive regulator of methyl jasmonate signaling in guard cells. Plant Physiol 55, 553-561.

Murata Y, Pei ZM, Mori IC, Schroeder JI (2001). Abscisic acid activation of plasma membrane $\mathrm{Ca}^{2+}$ channels in guard cells requires cytosolic $\mathrm{NAD}(\mathrm{P}) \mathrm{H}$ and is differentially disrupted upstream and downstream of reactive oxygen species production in abi1-1 and abi2-1 protein phosphatase 2C mutants. Plant Cell 13, 2513-2523.

Mustilli AC, Merlot S, Vavasseur A, Fenzi F, Giraudat J (2002). Arabidopsis OST1 protein kinase mediates the regulation of stomatal aperture by abscisic acid and acts upstream of reactive oxygen species production. Plant Cell 14, 3089-3099.

Negi J, Matsuda O, Nagasawa T, Oba Y, Takahashi H, Kawai-Yamada $M$, Uchimiya $H$, Hashimoto $M$, Iba $K$ (2008). $\mathrm{CO}_{2}$ regulator SLAC1 and its homologues are essential for anion homeostasis in plant cells. Nature $\mathbf{4 5 2}$, 483-486.

Neill S, Desikan R, Hancock J (2002). Hydrogen peroxide signaling. Curr Opin Plant Biol 5, 388-395.

Pallas JE Jr, Kays SJ (1982). Inhibition of photosynthesis by ethylene-a stomatal effect. Plant Physiol 70, 598-601.

Pei ZM, Murata Y, Bening G, Thomine S, Klüsener B, Allen GJ, Grill E, Schroeder JI (2000). Calcium channels activated by hydrogen peroxide mediate abscisic acid signaling in guard cells. Nature 406, 731-734.

Pham J, Desikan R (2009). ROS signaling in stomata. In: del Rio LA, Puppo A, eds. Reactive Oxygen Species in Plant Signaling. New York: Springer-Verlag. pp. 55-71.

Pnueli L, Liang HJ, Rozenberg M, Mittler R (2003). Growth suppression, altered stomatal responses, and augmented induction of heat shock proteins in cytosolic ascorbate peroxidase (Apx1)-deficient Arabidopsis plants. Plant $\mathrm{J}$ 34, 187-203.

Sagi M, Fluhr R (2006). Production of reactive oxygen species by plant NADPH oxidases. Plant Physiol 141,
336-340.

Salam MA, Jammes F, Hossain MA, Ye WX, Nakamura Y, Mori IC, Kwak JM, Murata Y (2012). MAP kinases, MPK9 and MPK12, regulate chitosan-induced stomatal closure. Biosci Biotechnol Biochem 76, 1785-1787.

Schroeder JI, Allen GJ, Hugouvieux V, Kwak JM, Waner D (2001). Guard cell signal transduction. Annu Rev Plant Physiol Plant Mol Biol 52, 627-658.

Sirichandra C, Gu D, Hu HC, Davanture M, Lee S, Djaoui M, Valot B, Zivy M, Leung J, Merlot S, Kwak JM (2009). Phosphorylation of the Arabidopsis AtrbohF NADPH oxidase by OST1 protein kinase. FEBS Lett 583, 2982-2986.

Song XG, She XP, He JM, Huang C, Song TS (2006). Cytokinin- and auxin-induced stomatal opening involves a decrease in levels of hydrogen peroxide in guard cells of Vicia faba. Funct Plant Biol 33, 573-583.

Srivastava N, Gonugunta VK, Puli MR, Raghavendra AS (2009). Nitric oxide production occurs downstream of reactive oxygen species in guard cells during stomatal closure induced by chitosan in abaxial epidermis of Pisum sativum. Planta 229, 757-765.

Suhita D, Raghavendra AS, Kwak JM, Vavasseur A (2004). Cytoplasmic alkalization precedes reactive oxygen species production during methyl jasmonate- and abscisic acid-induced stomatal closure. Plant Physiol 134, 1536-1545.

Sun LR, Hao FS, Lu BS, Ma LY (2010). AtNOA1 modulates nitric oxide accumulation and stomatal closure induced by salicylic acid in Arabidopsis. Plant Signal Behav 5, 1022-1024.

Tanaka Y, Sano T, Tamaoki M, Nakajima N, Kondo N, Hasezawa S (2005). Ethylene inhibits abscisic acidinduced stomatal closure in Arabidopsis. Plant Physiol 138, 2337-2343.

Tanaka Y, Sano T, Tamaoki M, Nakajima N, Kondo N, Hasezawa S (2006). Cytokinin and auxin inhibit abscisic acid-induced stomatal closure by enhancing ethylene production in Arabidopsis. J Exp Bot 57, 2259-2266.

Torres MA, Dangl JL, Jones JDG (2002). Arabidopsis gp9 ${ }^{\text {phox }}$ homologues AtrbohD and AtrbohF are required for accumulation of reactive oxygen intermediates in the plant defense response. Proc Natl Acad Sci USA 99, 517522.

Torres MA, Onouchi H, Hamada S, Machida C, Hammond-Kosack KE, Jones JDG (1998). Six Arabidopsis thaliana homologues of the human respiratory 
burst oxidase (gp91 ${ }^{\text {phox }}$ ). Plant J 14, 365-370.

Torsethaugen G, Pell EJ, Assman SM (1999). Ozone inhibits guard cell $\mathrm{K}^{+}$channels implicated in stomatal opening. Proc Natl Acad Sci USA 96, 13577-13583.

Vahisalu T, Kollist H, Wang YF, Nishimura N, Chan WY, Valerio G, Lamminmäki A, Brosché $M$, Moldau H, Desikan R, Schroeder JI, Kangasjärvi J (2008). SLAC1 is required for plant guard cell S-type anion channel function in stomatal signaling. Nature 452, 487-491.

Vahisalu T, Puzõrjova I, Brosché M, Valk E, Lepiku M, Moldau H, Pechter P, Wang YS, Lindgren O, Salojärvi J, Loog M, Kangasjärvi J, Kollist H (2010). Ozonetriggered rapid stomatal response involves the production of reactive oxygen species, and is controlled by SLAC1 and OST1. Plant J 62, 442-453.

Vavasseur A, Raghavendra AS (2005). Guard cell metabolism and $\mathrm{CO}_{2}$ sensing. New Phytol 165, 665-682.

Wang PT, Song CP (2008). Guard-cell signaling for hydrogen peroxide and abscisic acid. New Phytol 178, 703718.

Yan J, Tsuichihara N, Etoh T, Iwai S (2007). Reactive oxygen species and nitric oxide are involved in ABA inhibition of stomatal opening. Plant Cell Environ 30, 13201325.

Yoshida R, Hobo T, Ichimura K, Mizoguchi T, Takahashi F, Aronso J, Ecker JR, Shinozaki K (2002). ABA-activated SnRK2 protein kinase is required for dehydration stress signaling in Arabidopsis. Plant Cell Physiol 43, 1473-1483.

Yoshida R, Umezawa T, Mizoguchi T, Takahashi S, Takahashi F, Shinozaki K (2006). The regulatory domain of SRK2E/OST1/SnRK2.6 interacts with ABI1 and integrates abscisic acid (ABA) and osmotic stress signals controlling stomatal closure in Arabidopsis. J Biol Chem 281, 5310-5318.

Zhang W, Jeon BW, Assmann SM (2011). Heterotrimeric G-protein regulation of ROS signaling and calcium currents in Arabidopsis guard cells. J Exp Bot 62, 2371-2379.

Zhang X, Takemiya A, Kinoshita T, Schimazaki K (2007). Nitric oxide inhibits blue light-specific stomatal opening via abscisic acid signaling pathways in Vicia guard cells. Plant Cell Physiol 48, 715-723.

Zhang X, Wang HB, Takemiya A, Song CP, Kinoshita T, Shimazaki K (2004). Inhibition of blue light-dependent $\mathrm{H}^{+}$ pumping by abscisic acid through hydrogen peroxideinduced dephosphorylation of the plasma membrane $\mathrm{H}^{+}$-ATPase in guard cell protoplasts. Plant Physiol 136, 4150-4158.

Zhang X, Zhang L, Dong FC, Gao JF, Galbraith DW, Song CP (2001). Hydrogen peroxide is involved in abscisic acid-induced stomatal closure in Vicia faba. Plant Physiol 126, 1438-1448.

Zhang YY, Zhu HY, Zhang Q, Li MY, Yan M, Wang R, Wang LL, Welti R, Zhang WH, Wang XM (2009). Phospholipase Da1 and phosphatidic acid regulate NADPH oxidase activity and production of reactive oxygen species in ABA-mediated stomatal closure in Arabidopsis. Plant Cell 21, 2357-2377.

Zou JJ, Wei FJ, Wang C, Wu JJ, Ratnasekera D, Liu WX, Wu WH (2010). Arabidopsis calcium-dependent protein kinase CPK10 functions in abscisic acid- and $\mathrm{Ca}^{2+}$ mediated stomatal regulation in response to drought stress. Plant Physiol 154, 1232-1243. 


\title{
Reactive Oxygen Species Signaling in Stomata
}

\author{
Pengtao Wang ${ }^{\star}$, Jing Zhao, Huanhuan Yu \\ Henan Key Laboratory of Plant Stress Biology; State Key Laboratory of Cotton Biology; College of Life Sciences, Henan \\ University, Kaifeng 475004, China
}

\begin{abstract}
Reactive oxygen species (ROS) act as signaling molecules in stomata guard cells. ROS generation occurs in guard cells via specific enzymes. The most-studied enzymatic source is the NADPH oxidase component RBOH, which is involved in both abiotic and biotic stresses. Hormones, such as abscisic acid, salicylic acid, ethylene, auxin, and cytokinin, affect ROS-mediated responses in stomata. Biotic stresses, such as virulent bacteria and fungi, also affect stomata movements, where ROS likely play a role. Regulation of ROS production and action occurs at various levels, including antioxidant activities as well as ROS-sensitive proteins, such as kinases and phosphatases, which transduce ROS to affect stomatal closure. Evidence is gradually emerging of the ROS regulation of ion channels in stomata. Guard cells are an attractive model to study ROS signal transduction because of a complex integration of signaling pathways mediated via ROS.
\end{abstract}

Key words guard cell, reactive oxygen species, stomata

Wang PT, Zhao J, Yu HH (2014). Reactive oxygen species signaling in stomata. Chin Bull Bot 49, 490-503.

*Author for correspondence. E-mail: wangpt126@126.com

(责任编辑：白羽红) 